\title{
Metabolic Syndrome - A Bomb with Delayed Reaction
}

\author{
Genel $\mathrm{S}^{1,2 *}$, Emanuela $\mathrm{F}^{1}$ and Lucia $\mathrm{SM}^{1}$ \\ ${ }^{1}$ University of Medicine and Pharmacy, Iuliu Hatieganu, Cluj-Napoca, Romania \\ ${ }^{2}$ Emergency Clinical Hospital for Children, Cluj-Napoca, Romania
}

\begin{abstract}
Premise: According to the International Diabetes Federation (IDF) consensus worldwide 2013 the metabolic syndrome is a cluster of the most dangerous heart attack risk factors: diabetes and raised fasting plasma glucose, abdominal obesity, high cholesterol and high blood pressure. It is known that about $20-25 \%$ of the world population has metabolic syndrome. The risk of dying through complications such as heart attack or stroke is two to three times higher than the general population. Platinum standard definition (IDF) proposed for including metabolic syndrome in addition to other measurements determination of pro-inflammatory status.
\end{abstract}

Objectives: Identifying inflamation and its severity using inflamatory markers: C-reactive protein fibrinogen and leukocytes. Assesment of these markers considering the diversity of metabolic syndrome elements.

Material and method: We performed a study that enrolled 152 patients registered to a family physician and diagnosed with metabolic syndrome. The subjects included in study were divided in two groups: group A-78 subjects diagnosed with metabolic syndrome that was defined by 3 elements: abdominal obesity+arterial hypertension+diabetes mellitus; group B-74 patients diagnosed with metabolic syndrome based on 5 elements: abdominal obesity+arterial hypertension+diabetes mellitus+decreased high density lipoprotein+increased triglycerides. We also established a control group-30 healthy people to compare inflammatory markers values.

Results: We observed increased values of CRP fibrinogen and leukocytes for group B in comparison to group A: $0.9 \pm 0.8 \mathrm{mg} / \mathrm{dl}$ vs $0.79 \pm 0.8 \mathrm{mg} / \mathrm{dl}(p=0.02$, significantly statistic)Fibrinogen increased in group $B$ significantly in comparison to group A $(442,35$ versus $365,8 p=0,0006$. Leukocytes level was less responsive in patients with metabolic syndrome; leukocytes value was higher for group $B$, but not significantly statistic.

Conclusions: Inflammation in patients with metabolic syndrome depends on the number and association of elements that define this entity, being more accentuated for subjects who associate more elements.

Keywords: Metabolic syndrome; Inflammation; Markers

\section{Background}

Metabolic syndrome (MetS) is an entity that represents a global health problem. It is a multiplex risk factor thar arises from insulin resistance acompanying abnormal adipose tissue [1]. According to the IDF definition (2013), for a person to be defined as having the metabolic syndrome, it must have central obesity plus any two of the following factors: raised triglycerides $(\geq 150 \mathrm{mg} / \mathrm{dL})$ or specific treatment for this lipid abnormality, reduced HDL cholesterol $(<40 \mathrm{mg} / \mathrm{dL}$ in males, $<50 \mathrm{mg} / \mathrm{dL}$ in females ) or specific treatment for this lipid abnormality, raised blood pressure (systolic $\mathrm{BP} \geq 130$ or diastolic $\mathrm{BP} \geq 85 \mathrm{~mm} \mathrm{Hg}$ ) or treatment of previously diagnosed hypertension, raised fasting plasma glucose $((\mathrm{FPG}) \geq 100 \mathrm{mg} / \mathrm{dL})$ or previously diagnosed type 2 diabetes $[1,2]$. In addition to clinical parameters, mentioned in the definition of metabolic syndrome, IDF describes the 'platinum standard' definition - additional metabolic measurements for research. These additional measurements include the following: abnormal body fat distribution (general body fat distribution, central fat distribution, adipose tissue biomarkers: leptin, adiponectin, and liver fat content),[3] insulin resistance (fasting insulin/proinsulin levels, HOMA-IR, insulin resistance by Bergman Minimal Model, elevated free fatty acids, $\mathrm{M}$ value from clamp), atherogenic dyslipidaemia (ApoB Small LDL particles), dysglycaemia (OGTT), pro-inflammatory state (elevated high sensitivity C-reactive protein, elevated inflammatory cytokines, decrease in adiponectin plasma levels), [4-7] vascular dysregulation (measurement of endothelial dysfunction, microalbuminuria), prothrombotic state (fibrinolytic factors, clotting factors), hormonal factors (pituitary-adrenal axis) [1-9]. Abundent data suggests that patients meeting these diagnostic criteria have a greater risk of having significant clinical consequences: doubled risk of coronary artery disease, increased risk of stroke, fatty liver disease, diabetes and cancer $[10,11]$.

\section{Material and Methods}

We performed a study that enrolled 152 subjects with metabolic syndrome registered to a family physician. The group of study is significant for Transylvania region as, to the family physician are registered people from both urban and rural areas, from Cluj county and also from bordered counties. The study was carried on from 2009 to 2010. We had patients agreement to participate in the study. Subjects admitted in the study were divided in two groups: group A 78 subjects diagnosed with metabolic syndrome that was defined by 3 elements: abdominal obesity+arterial hypertension+diabetes mellitus; group B - 74 patients diagnosed with metabolic syndrome based on 5 elements: abdominal obesity+arterial hypertension+diabetes mellitus+decreased high density lipoprotein+increased triglycerides. Patients distribution in group A, considering the three elements, was unitary. We also formed a control group that consisted of 30 healthy

*Corresponding author: Genel S, University of Medicine and Pharmacy Iuliu Hatieganu, Cluj-Napoca, Romania, Tel: 0040724504964; E-mail: surgenel@yahoo.com

Received December 26, 2014; Accepted April 14, 2015; Published April 30, 2015

Citation: Genel S, Emanuela F, Lucia SM (2015) Metabolic Syndrome - A Bomb with Delayed Reaction. J Bioequiv Availab 7: 155-157. doi:10.4172/jbb.1000231

Copyright: @ 2015 Genel S, et al. This is an open-access article distributed under the terms of the Creative Commons Attribution License, which permits unrestricted use, distribution, and reproduction in any medium, provided the original author and source are credited. 
people with the same age as the subjects included in the study group. We assesed inflammatory status for patients from the two study groups and for the control group using as inflammatory markers: Creactive protein fibrinogen and leukocytes. We considered as normal values for leukocytes: 5000-10000/ $\mu$ l. C-reactive protein was evaluated through a quantitative technique and we considered as normal values: $0.1-0.8 \mathrm{mg} / \mathrm{dl}$. We considered as normal values for fibrinogen $200-$ $400 \mathrm{mg} \%$ Inflammatory markers values obtained for the two study groups were compared with values obtained for the control group. We excluded from the study people who presented other morbide conditions beside metabolic syndrome as there was a posibility to interfere with the results obtained for inflammatory markers: chronic pulmonary disease, chronic kidney failure, (creatinine $>1.2 \mathrm{mg} / \mathrm{dl}$ ), record of neoplasm or actual neoplasia, pulmonary microembolism, chronic focal infections, recent acute infections, colagenous diseases, nonsteroidian antiinflammatory therapy or cortisone therapy, surgery in the past six months, acute myocardial infarction or stroke. Statistics used SPSS 13.0 Statistical Sofware Package (SPSS Inc Illinois USA). Data were expressed with standard life average. For testing differencies were used parameters Mann-Whitney and Kruskall-Valis. A value of $\mathrm{p}<0.05$ was considered significant statistic.

\section{Results}

Out of all 152 subjects submitted to the study, 89 were males, representing $44.5 \%$ and 63 were females, representing 55.5\%. Average age was $55.9 \pm 11$ years. Men average age was $55.1 \pm 11.5$ years, while women average age was $61.5 \pm 10$ years, meaning a significantly statistic difference $(\mathrm{p}=0.03)$.

For inflammatory biomarkers we observed increased values of CRP for group B in comparison to group A, with a significant statistic difference $(p=0.02)$. Fibrinogen increased for group $B$ in coparison to group A with a significant statistic difference $(442,35$ versus 365,82 $\mathrm{p}=0,0006)$

Leukocytes level was less responsive in patients with metabolic syndrome in comparison to CRP revealing that leukocytes have a less important value in establishing proinflammatory and cardiovascular risk contribution in patients with metabolic syndrome. Values of inflammatory markers in individuals from the control group consisting of 30 subjects aged approximately equal to the patients in the study were normal.

\section{Disscusion}

Our study is very actual as metabolic syndrome is very important for current medical practice due to a progressive increasing frequency and atherogenic risk. Metabolic syndrome may affect most of the population and it may generate both vascular and metabolic complications [1,12-14].

Inflammation factors that define the metabolic syndrome are related to inflammatory cytokine produced by various cell types. These cytokines are released into the circulation and regulate various tissues, thus having the central and peripheral actions. In the literature is clear that cytokines play a major role in the development of type 2 diabetes, but the ability to reduce inflammation and thus the risk of developing type 2 diabetes is still under study.

Our study outlines an important mechanism: proinflammatory injury as a base of cardiovascular risk. Proinflammatory activity is more significant if metabolic syndrome is characterised by more elements (group B is defined by 5 elements and group A by 3 elements).
The results we obtained find that inflammatory status is increased in patients diagnosed with metabolic syndrome (statistically significant, in subjects that associate more than 3 elements). Inflammatory injury has different severity depending on the elements that define metabolic syndrome and on their association. Out of these elements, hypertension has a less expressed contribution in comparison to triglycerides, HDL-C, glycemia values. Once the inflammation level increases there is a differentiated prognostic impact for cardiovascular events $[15,16]$.

Metabolic syndrome frequency is progressively increasing and evaluation of proinflammatory risk of this entity is valuable, as assesment of some inflammatory biomarkers implies minimum costs and it can be repeated [17-20]. In our study CRP and fibrinogen proved to be an accurate indicator of inflammation existance for patients with metabolic syndrome. In subjects with acute coronary syndrome, stroke, periferic vascular disease and sudden death, recent epidemiological data ascertained a positive association between CRP, fibrinogen levels and clinic manifestations of atherosclerosis atherotrhtrombosis. Increased values of CRP and fibrinogen are a predictive marker for unfavourable/ improper evolution at patients with unstable angina pectoris after myocardial revascularisation, as well as in patients with metabolic syndrome and diabetes - that suggests its role in atherogenesis [21-25]

Leukocytes increase more evidentely in acute vascular complications that may occur in these subjects. These markers seem to be a less valuable marker for chronic inflammatory character. In our study leukocytes value, even if it was increased for group B in comparison to group A, was not significantly statistic [26,27].

\section{Conclusions}

Patients diagnosed with metabolic syndrome present an activated inflammatory status.

In subjects with metabolic syndrome, defined by more than 3 elements, inflammatory status is more increased. Bioumoral components of metabolic syndrome have a higher proinflammatory contribution. Inflammatory status in patients with metabolic syndrome increases the risk of atherogenesis, type 2 diabetes and heart complications.

\section{References}

1. Alberti SG, Zimmet P (2013) IDF Consensus Worldwide Definition of the Metabolic Syndrome.

2. Simmons RK, Alberti KG, Gale EA, Colagiuri S, Tuomilehto J, et al. (2010) The metabolic syndrome: useful concept or clinical tool? Report of a WHO Expert Consultation. Diabetologia 53: 600-605.

3. Piya MK, McTernan PG, Kumar S (2013) Adipokine inflammation and insulin resistance: the role of glucose, lipids and endotoxin. J Endocrinol 216: T1-1T15.

4. Grundy SM (2011)The Metabolic Syndrome.Atlas of Atherosclerosis and Metabolic Syndrome. 1-26

5. Maury E, Brichard SM (2010) Adipokinedysregulation, adipose tissue inflammation and metabolic syndrome. Mol Cell Endocrinol 314: 1-16.

6. Monteiro R, Azevedo I (2010) Chronic inflammation in obesity and the metabolic syndrome. Mediators Inflamm 2010.

7. Lehrke M, Becker A, Greif M, Stark R, Laubender RP, et al. (2009) Chemerin is associated with markers of inflammation and components of the metabolic syndrome but does not predict coronary atherosclerosis. Eur J Endocrinol 161: 339-344.

8. Mente A, Yusuf S, Islam S, McQueen MJ, Tanomsup S, et al. (2010) Metabolic syndrome and risk of acute myocardial infarction a case-control study of 26,903 subjects from 52 countries. J Am CollCardiol 55: 2390-2398.

9. Després JP, Lemieux I, Bergeron J, Pibarot P, Mathieu P, et al. (2008) 
Abdominal obesity and the metabolic syndrome: contribution to global cardiometabolic risk. Arterioscler Thromb Vasc Biol 28: 1039-1049.

10. Grundy SM (2007) Metabolic syndrome: a multiplex cardiovascular risk factor. $\mathrm{J}$ Clin Endocrinol Metab 92: 399-404.

11. Camhi SM, Stefanick ML, Ridker PM, Young DR (2010) Changes in C-reactive protein from low-fat diet and/or physical activity in men and women with and without metabolic syndrome. Metabolism 59: 54-61.

12. Devaraj S, Singh U, Jialal I (2009) Human C-reactive protein and the metabolic syndrome. CurrOpinLipidol 20: 182-189.

13. Gustafson B, Hammarstedt A, Andersson CX, Smith U (2007) Inflamed adipose tissue: a culprit underlying the metabolic syndrome and atherosclerosis. Arterioscler Thromb Vasc Biol 27: 2276-2283.

14. Olufadi R, Byrne CD (2008) Clinical and laboratory diagnosis of the metabolic syndrome. J Clin Pathol 61: 697-706.

15. Vrolix R, van Meijl LE, Mensink RP (2008) The metabolic syndrome in relation with the glycemic index and the glycemic load. Physiol Behav 94: 293-299.

16. Tilg $H$, Moschen AR (2008) Inflammatory mechanisms in the regulation of insulin resistance. Mol Med 14: 222-231.

17. Cheng AY, Leiter LA (2006) Metabolic syndrome under fire: weighing in on the truth. Can J Cardiol 22: 379-382.

18. Visser M, Bouter LM, McQuillan GM, Wener MH, Harris TB (1999) Elevated C-reactive protein levels in overweight and obese adults. JAMA 282: 21312135.

19. Florez H, Castillo-Florez S, Mendez A, Casanova-Romero P, Larreal-Urdaneta C, et al. (2006) C-reactive protein is elevated in obese patients with the metabolic syndrome. Diabetes Res Clin Pract 71: 92-100.
20. Rifai N (2005) High-sensitivity C-reactive protein: a useful marker for cardiovascular disease risk prediction and the metabolic syndrome. ClinChem 51: 504-505.

21. LaaksonenDE, Niskanen L, Nyyssönen K, Punnonen K, Tuomainen TP, et al. (2005) C-reactive protein in the prediction of cardiovascular and overall mortality in middle-aged men: a population-based cohort study. Eur Heart $J$ 26: $1783-1789$.

22. Ridker PM, Buring JE, Cook NR, Rifai N (2003) C-reactive protein, the metabolic syndrome, and risk of incident cardiovascular events: an 8-year follow-up of 14 719 initially healthy American women. Circulation 107: 391-397.

23. Rutter MK, Meigs JB, Sullivan LM, D'Agostino RB Sr, Wilson PW (2004) C-reactive protein, the metabolic syndrome, and prediction of cardiovascular events in the Framingham Offspring Study. Circulation 110: 380-385.

24. Timpson NJ, Lawlor DA, Harbord RM, Gaunt TR, Day IN, et al. (2005) $\mathrm{C}$-reactive protein and its role in metabolic syndrome: mendelian randomisation study. Lancet 366: 1954-1959.

25. Tsai JC, Sheu SH, Chiu HC, Chung FM, Chang DM, et al. (2007) Association of peripheral total and differential leukocyte counts with metabolic syndrome and risk of ischemic cardiovascular diseases in patients with type 2 diabetes mellitus. Diabetes Metab Res Rev 23:111-118.

26. Desai MY, Dalal D, Santos RD, Carvalho JA, Nasir K, et al. (2006) Association of body mass index, metabolic syndrome, and leukocyte count. Am J Cardiol 97: 835-838.

27. Kempf K, Rose B, Herder C, Haastert B, Fusbahn-Laufenburg A, et al. (2007) The metabolic syndrome sensitizes leukocytes for glucose-induced immune gene expression. J Mol Med (Berl) 85: 389-396. 